\title{
FORMAÇ̃̃o DE MULTICAMADAS DE POLISSACARÍDEOS E PROTEÍNA
}

\author{
Juliana Fujimoto, Eduardo Alexandre de Oliveira Reis e Denise F. S. Petri* \\ Instituto de Química, Universidade de São Paulo, CP 26077, 05513-970 São Paulo - SP \\ Sérgio P. Campana Filho \\ Instituto de Química de São Carlos, Universidade de São Paulo, CP 780, 13560-970 São Carlos - SP
}

Recebido em 27/8/01; aceito em 9/11/01

\begin{abstract}
FORMATION OF POLYSACCHARIDES AND PROTEIN MULTILAYERS. In this work the formation of multilayers composed by carboxymethylcellulose (CMC), chitosane and bovine serum albumin (BSA) was studied by ellipsometry. First, the adsorption behavior of carboxymethylcellulose onto amino-terminated surfaces was investigated as a function of molecular weight and average degree of substitution of CMC. The influence of these parameters on the adsorbed amount of CMC onto amino-terminated substrates was absent. However, the interaction of CMC covered surfaces with chitosane and BSA was favored when the average degree of substitution of CMC was increased. The adsorption of BSA onto the polysaccharide systems was studied as a function of $\mathrm{pH}$. At the isoelectric point of BSA a maximum in the adsorbed amount was found.
\end{abstract}

Keywords: polysaccharides; ellipsometry; bovine serum albumin.

\section{INTRODUÇÃO}

A formação de filmes finos de polissacarídeos sobre superfícies sólidas tem relevância acadêmica e tecnológica, como por exemplo em processos de estabilização coloidal ${ }^{1}$ e no desenvolvimento de biossensores e imunoensaios ${ }^{2,3}$. A carboximetilcelulose (CMC) é um derivado de celulose produzido, via reação de Williamson, pelo tratamento de celulose com ácido monocloroacético em presença de excesso de hidróxido de sódio ${ }^{4}$. É um importante produto industrial, geralmente isolado e comercializado como sal de sódio, que apresenta as seguintes vantagens: (i) pode ser produzido à pressão atmosférica (diferentemente da maioria dos éteres de celulose); (ii) a presença de grupos carboxilatos lhe confere solubilidade em água quando o grau médio de substituição $(\overline{G S})$ é maior que 0,5 e (iii) pode ser obtido a partir de biomassa abundante e barata, como o bagaço da cana-de-açúcar proveniente de usinas de açúcar e álcool ${ }^{5}$. A adsorção de carboximetil celulose (CMC) sobre substratos sólidos está bem reportada na literatura ${ }^{6-8}$. Em trabalho prévio ${ }^{8}$, verificou-se a forte influência do $\mathrm{pH}$ e da força iônica do meio sobre a adsorção de CMC sobre superfícies amino-funcionalizadas. Neste sistema, a variação do $\mathrm{pH}$ do meio provoca mudanças nas densidades de carga da CMC e do substrato. Em pH próximo a 4, a CMC se comporta como um polieletrólito fraco, pois a maioria dos grupos carboximetila porta cargas negativas resultantes de sua ionização ${ }^{9}$, enquanto as aminas primárias se apresentam na forma protonada e, portanto, possuem cargas positivas. Um máximo de adsorção foi observado na faixa de $\mathrm{pH}$ entre 3 e 4 , indicando que, de fato, a força motriz que favorece as interações entre substrato e adsorbato é de natureza eletrostática. A adsorção também foi favorecida em baixa força iônica, seguindo o regime de redução de adsorção por blindagem reduzida ("screening-reduced adsorption" regime) proposto por van de Steeg ${ }^{10}$ e colaboradores. Este efeito é explicado com base no fato que os íons provenientes da dissociação do sal que foi adicionado para manter a força iônica do meio blindam não só as cargas dos segmentos do polieletrólito, diminuindo as repulsões intra e intermole-

\footnotetext{
*e-mail: dfsp@quim.iq.usp.br
}

culares, mas também as interações entre o substrato e os segmentos das cadeias polieletrolíticas. O efeito do $\mathrm{pH}$ na formação de filmes finos de polieletrólitos fracos foi recentemente reportado na literatu$\mathrm{ra}^{11,12}$. Shiratori e Rubner ${ }^{11}$ mostraram que uma pequena variação de pH pode elevar a espessura de filmes de policátions e poliânions adsorvidos de $0,5 \mathrm{~nm}$ para $8 \mathrm{~nm}$.

O efeito da massa molar e do grau de substituição sobre a adsorção de polieletrólitos sobre superfícies sólidas está pouco explorado na literatura ${ }^{7}$. Neste trabalho estudou-se, em uma primeira etapa, a adsorção da carboximetilcelulose sobre superfícies aminofuncionalizadas em função da massa molar e do grau médio de substituição da CMC através de elipsometria. Subseqüentemente estudou-se a adsorção de quitosana, polissacarídeo obtido pela desacetilação de quitina, e de albumina bovina sérica (BSA) sobre as superfícies recobertas com CMC. A quitosana possui muitas aplicações tecnológicas e é utilizada, por exemplo, no tratamento de efluentes industriais devido à sua facilidade de interagir com as partículas coloidais e devido, também, à presença de grupos amino em suas cadeias, o que confere a esse polímero um potencial de coagulação maior que o dos coagulantes usuais. Quitosana também é aplicada na área médica, na forma de um fio fino, biocompatível e resistente usado para suturas cirúrgicas ${ }^{13}$. A albumina (BSA), foi escolhida como proteína-modelo por ser um dos principais componentes do sangue e por ter larga aplicação em diagnósticos ${ }^{14}$.

\section{MATERIAIS UTILIZADOS}

Amostras de carboximetilcelulose (CMC) foram obtidas a partir da derivatização de polpas branqueadas de bagaço de cana-de-açúcar ${ }^{5}$, e suas massas molares médias viscosimétricas $\left(\bar{M}_{V}\right)$ e graus médios de substituição ( $\overline{G S})$ são mostrados na Tabela 1. 3aminopropiltrimetoxisilano (APS) e quitosana (massa molar média nominal de $150.000 \mathrm{~g} \mathrm{~mol}^{-1}$ ) foram fornecidos pela Fluka (Basel, Suíça). Albumina bovina sérica (BSA) foi obtida da Sigma (E.U.A). Cloreto de sódio p.a, ácido clorídrico, ácido acético glacial p.a. e tolueno foram adquiridos da Nuclear (São Paulo). Lâminas de Si (recobertas com uma camada de $\mathrm{SiO}_{2}$ nativo) foram fornecidas pela CrysTec (Alemanha). 
Tabela 1. Características das amostras de CMC obtidas a partir de bagaço de cana-de-açúcar

\begin{tabular}{lcc}
\hline Amostra & $\overline{\mathrm{M}}_{\mathrm{v}}(\mathrm{g} / \mathrm{mol})$ & $\overline{G S}$ \\
\hline CMC1 & 76.000 & 0,8 \\
CMC2 & 113.570 & 0,8 \\
CMC3 & 76.000 & 1,5 \\
CMC4 & 98.390 & 1,5 \\
CMC5 & 59.000 & 1,8 \\
CMC6 & 76.470 & 1,8 \\
CMC7 & 149.700 & 1,8 \\
\hline
\end{tabular}

\section{MÉTODOS}

\section{Silanização}

As superfícies amino-funcionalizadas foram obtidas a partir da reação de silanização das lâminas de Si com $\mathrm{APS}^{15}$. Primeiramente as lâminas de silício foram limpas, imergindo-as em uma mistura oxidativa contendo $\mathrm{H}_{2} \mathrm{O}_{2}, \mathrm{NH}_{3}$ e $\mathrm{H}_{2} \mathrm{O}$, na proporção de 1:1:4 em volume, à temperatura de $75^{\circ} \mathrm{C}$, durante $20 \mathrm{~min}$. Depois desse período retirou-se as lâminas da mistura, lavou-se em água destilada e secouse com jatos de nitrogênio. Após serem limpas as lâminas foram mergulhadas em uma solução de APS em tolueno ( $1 \%$ em volume) a $60{ }^{\circ} \mathrm{C}$ durante $5 \mathrm{~min}$, sendo lavadas em seguida em tolueno puro e secas com jatos de nitrogênio. Através deste método, obtém-se uma monocamada amino-funcionalizada homogênea ${ }^{15}$ covalentemente ligada à lâmina de silício.

\section{Elipsometria}

Elipsometria ${ }^{16}$ consiste em medir a mudança do estado de polarização da luz após a reflexão, a partir de uma superfície isotrópica refletora. As mudanças de fase $(\Delta)$ e de amplitude $(\psi)$ da radiação após a reflexão são medidos com relação à radiação incidente. $\Delta \mathrm{e} \psi$ dependem do comprimento de onda da radiação $(\lambda)$, do ângulo de incidência $(\phi)$, da espessura (d) e do índice de refração (n) de um filme isotrópico e refletor, como mostra a equação fundamental da elipsometria $^{16}$ (eq. 1):

$\tan \psi \mathrm{e}^{\mathrm{i} \Lambda}=\mathrm{f}(\mathrm{n}, \mathrm{d}, \phi \mathrm{e} \lambda)$

Através da equação 1, das relações de Drude e Fresnel, de cálculos interativos e matrizes de Jones ${ }^{16}$ pode-se obter $\mathrm{n}$ e d independentemente. Quando as espessuras das camadas são muito finas $(\approx 1 \mathrm{~nm})$ ou quando o contraste óptico não é suficiente para que d e n sejam obtidos independentemente um do outro, então, usa-se o índice de refração fixo a partir de dados da literatura ou do fabricante, e determina-se a espessura do filme $\left(\mathrm{d}_{\text {poli }}\right)$. Usou-se os seguintes índices de refração: $\mathrm{Si}: \mathrm{n}=3.858-0.018 \mathrm{i}^{17}$; $\mathrm{SiO}_{2}{ }^{17} \mathrm{n}=1,462$; APS: $\mathrm{n}=1,424$ (Fluka); CMC: $\mathrm{n}=1,50^{18}$; Quitosana ${ }^{13} \mathrm{n}=1,50$; BSA $^{14} \mathrm{n}=1.52$. As medidas elipsométricas foram realizadas num elipsômetro DREELX02 (Ratzeburg, Alemanha) equipado com um laser He-Ne $(\lambda=632.8 \mathrm{~nm})$, com ângulo de incidência ajustado em $70^{\circ}$. Todas as medidas foram feitas in situ numa cela elipsométrica especialmente desenhada para estas medidas ${ }^{8}$, onde a cada 3 seg valores de $\Delta$ e $\psi$ foram automaticamente registrados.

A quantidade de material adsorvido $\Gamma\left(\mathrm{mg} / \mathrm{m}^{2}\right)$ foi calculado através da equação $2^{8,19,20}$ :

$\Gamma=\frac{\mathrm{d}_{\text {poli }}\left(\mathrm{n}_{\text {poli }}-\mathrm{n}_{0}\right)}{\mathrm{dn} / \mathrm{dc}}=\mathrm{d}_{\text {poli }} \mathrm{c}_{\text {poli }}$ onde $\mathrm{n}_{0}$ é o índice de refração da solução medido por um refratômetro Abbe, dn/dc é o incremento do índice de refração determinado por um refratômetro diferencial e $\mathrm{c}_{\text {poli }}$ é a concentração média dentro da camada. Para os presentes sistemas, $\mathrm{n}_{0}$ foi medido para cada concentração e $\mathrm{dn} / \mathrm{dc}$ foi determinado como sendo $0.16 \mathrm{ml} / \mathrm{g}$ à temperatura de $23{ }^{\circ} \mathrm{C}$.

\section{RESULTADOS E DISCUSSÃO}

\section{Efeito da massa molar sobre as isotermas de adsorção}

Para determinar-se a influência da massa molar na adsorção da CMC utilizou-se soluções de CMC5, CMC6 e CMC7, as quais apresentam $\overline{G S}=1,8$, preparadas em ácido acético $0,1 \mathrm{~mol} / \mathrm{L}$ e $\mathrm{NaCl}$ $0,001 \mathrm{~mol} / \mathrm{L}$, na faixa de concentração de $0,005 \mathrm{~g} / \mathrm{L}$ a $1,0 \mathrm{~g} / \mathrm{L}$, mantendo o pH em 3,5. Neste $\mathrm{pH}$, as interações eletrostáticas entre substrato e adsorbato são favorecidas ${ }^{8}$. Após $1 \mathrm{~h}$ de adsorção os valores de $\Delta$ e $\psi$ não variaram mais, indicando que o equilíbrio de adsorção tinha sido atingido. Os resultados apresentados na Figura 1 não indicam, dentro do erro experimental, diferenças significativas no platô de adsorção e na afinidade entre substrato e adsorbato quando variamos a massa molar da CMC. Efeitos semelhantes foram observados por Hoogendam e colaboradores ${ }^{6}$ no estudo da adsorção de CMC sobre hematita. Estes resultados são explicados através da conformação estendida que as cadeias assumem quando adsorvidas.

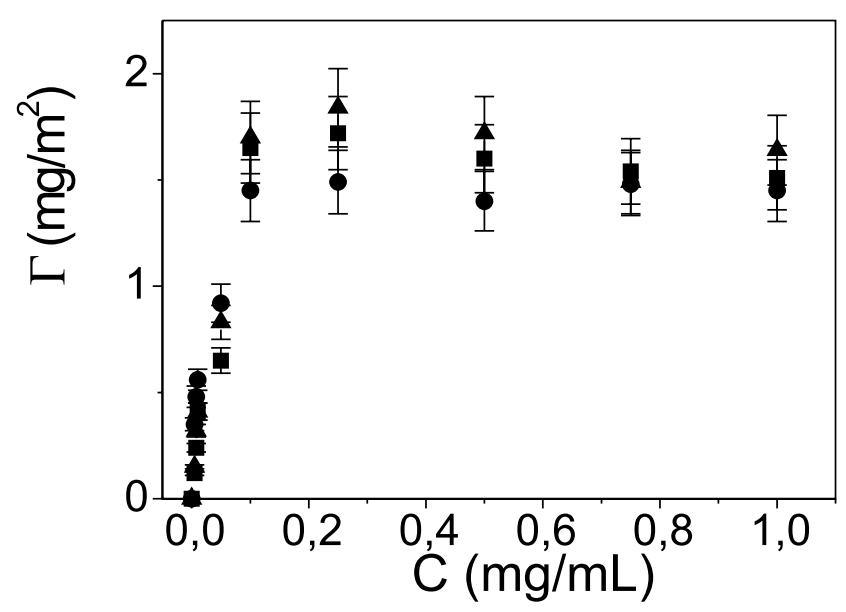

Figura 1: Isotermas de adsorção obtidas para $C M C(\overline{G S}=1,8) \mathrm{em} \mathrm{NaCl}$ 0,001M/ HAc 0,1M sobre superfícies amino funcionalizadas. (口) $59.000 \mathrm{~g} /$ mol; (A) $78.470 \mathrm{~g} / \mathrm{mol} \mathrm{e}(\bullet) 149.700 \mathrm{~g} / \mathrm{mol}$

Efeito do grau médio de substituição $(\overline{G S})$ sobre as isotermas de adsorção

Nestes experimentos a massa molar média viscosimétrica da CMC foi mantida fixa em $76.000 \mathrm{~g} / \mathrm{mol}$, enquanto o grau médio de substituição $(\overline{G S})$ variou de 0,8 a 1,8 . As soluções de CMC foram preparadas em ácido acético $0,1 \mathrm{~mol} / \mathrm{L}$ e $\mathrm{NaCl} 0,001 \mathrm{~mol} / \mathrm{L}$, na faixa de concentração de $0,005 \mathrm{~g} / \mathrm{L}$ a 1,0 g/L, mantendo o pH em 3,5. Após $1 \mathrm{~h}$ de adsorção o equilíbrio de adsorção tinha sido atingido. Os resultados obtidos (Figura 2) demonstram que não existe nenhuma influência do grau médio de substituição na adsorção de CMC sobre superfícies silanizadas. Os grupos carboxilatos estão distribuídos aleatoriamente ao longo das cadeias, de modo que a adsorção ocorre através da ancoragem de vários segmentos de uma mesma cadeia sobre a superfície. Conseqüentemente as cadeias adsorvidas assumem conformação aleatória. Assim, estes polieletrólitos tem o comportamento semelhante ao de homopolímeros ou copolímeros estatísticos, onde 
as cadeias adsorvidas formam "loops" e "tails" sobre a superfície. Desta forma, o aumento de $\overline{G S}$ poderá aumentar o número de pontos de ancoragem sobre a superfície, mas não a quantidade de material adsorvido. A afinidade entre adsorbato e substrato também parece não depender do grau de substituição.

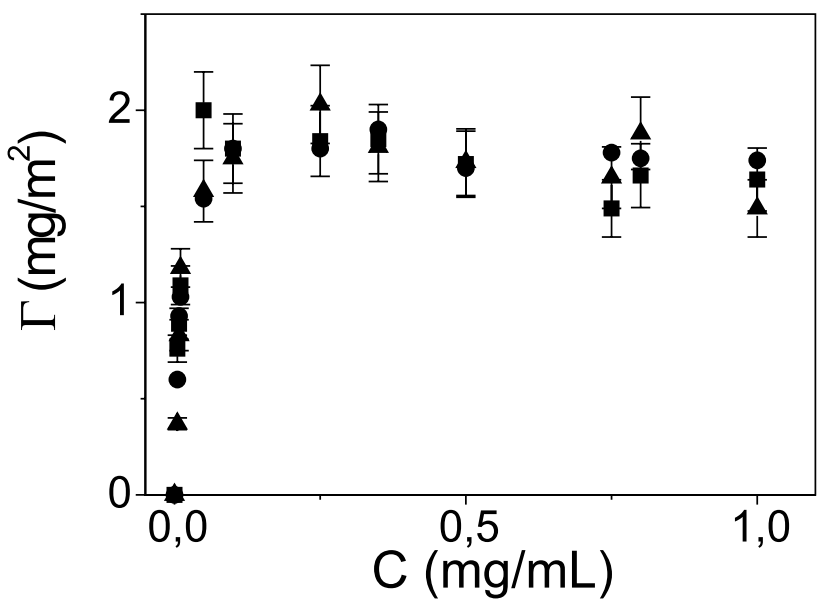

Figura 2: Isotermas de adsorção obtidas para CMC $\left(\bar{M}_{v}=76.000 \mathrm{~g} / \mathrm{mol}\right)$ em $\mathrm{NaCl}$ 0,001M/ HAc 0,1M sobre superfícies amino funcionalizadas. ( $\mathbf{\Delta})$ $\overline{G S}=0,8 ;(\bullet) \overline{G S}=1,5 e(\mathbf{\square}) \overline{G S}=1,8$

\section{Ensaios de dessorção}

Após 4 h de adsorção de CMC7 sobre as superfícies amino funcionalizadas, a solução de polieletrólito foi trocada por solvente puro (solução aquosa de $\mathrm{HAc} 0,1 \mathrm{~mol} / \mathrm{L} \mathrm{e} \mathrm{NaCl} 0,001 \mathrm{~mol} / \mathrm{L}$ ) em $\mathrm{pH}$ 4,5 e pH 6,5, a fim de se verificar se há a dessorção da CMC em função do tempo e do pH. A Figura 3 mostra que não há diminuição da quantidade de material adsorvido em função do tempo, indicando que não ocorre dessorção de CMC nestas condições experimentais por um período de até $24 \mathrm{~h}$. As interações eletrostáticas certamente estão enfraquecidas na faixa de $\mathrm{pH}$ testada, pois a protonação das aminas primárias presentes no substrato é desfavorecida, mas ligações de hidrogênio entre as hidroxilas das cadeias de CMC e as aminas mantêm as cadeias adsorvidas.

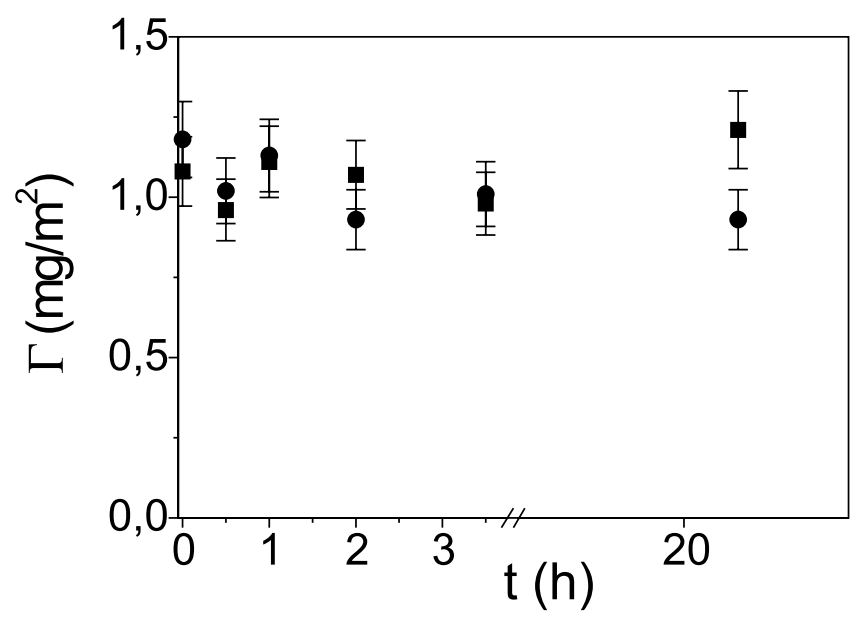

Figura 3: Ensaios de dessorção. Quantidade de CMC $\left(\bar{M}_{v}=149.700, \overline{G S}\right.$ $=1,8$ ) adsorvida sobre superfícies amino-funcionalizadas após a troca da solução polimérica por em água destilada em função do tempo em pH 4,6 (ロ) e pH 6,5 (•)

\section{Adsorção de quitosana sobre CMC com diferentes $\overline{G S}$}

Superfícies silanizadas e com monocamadas de CMC1 e CMC6 depositadas foram colocadas em contato com soluções de quitosana na concentração de $1 \mathrm{~g} / \mathrm{L}$ preparadas em HAc $0,1 \mathrm{~mol} / \mathrm{L}(\mathrm{pH} 3) \mathrm{e}$ forças iônicas variando de $0,0005 \mathrm{~mol} / \mathrm{L} \mathrm{a} 0,01 \mathrm{~mol} / \mathrm{L}$ de $\mathrm{NaCl}$. Após $18 \mathrm{~h}$ de adsorção as superfícies foram lavadas com o solvente e secas com jatos de $\mathrm{N}_{2}$. Nestes sistemas a massa molar média viscosimétrica da CMC foi mantida constante e o $\overline{G S}$ foi variado de 0,8 (CMC1) para 1,8 (CMC6). Através de medidas elipsométricas, as espessuras dos filmes de quitosana foram determinadas no ar. No caso de sistemas de quitosana adsorvida sobre $\mathrm{CMC} 1$, a espessura média medida foi de 0,4 $\pm 0,2 \mathrm{~nm}$ independente da força iônica, como mostra a Figura 4. Já no caso de sistemas onde o substrato era formado por filmes de CMC6, a espessura média do filme de quitosana adsorvida aumentou linearmente com a força iônica do meio. Estes resultados indicam que a quitosana adsorve mais fortemente sobre $\mathrm{CMC}$ de maior $\overline{G S}$ (CMC6). Em pH 3 os grupos carboxilatos da CMC estão fracamente carregados, ou seja, há poucas cargas livres para interagir com a quitosana que, neste $\mathrm{pH}$, está positivamente carregada. Portanto, quanto maior o $\overline{G S}$ da CMC, maior é o número de cargas disponíveis para interagir com a quitosana. As amostras foram preparadas em triplicatas e medidas em quatro pontos diferentes da superfície, observando-se uma variação de espessuras entre os pontos medidos de 5 até $50 \%$. Estes resultados indicam que a quitosana provavelmente adsorve formando aglomerados, e não um filme homogêneo.

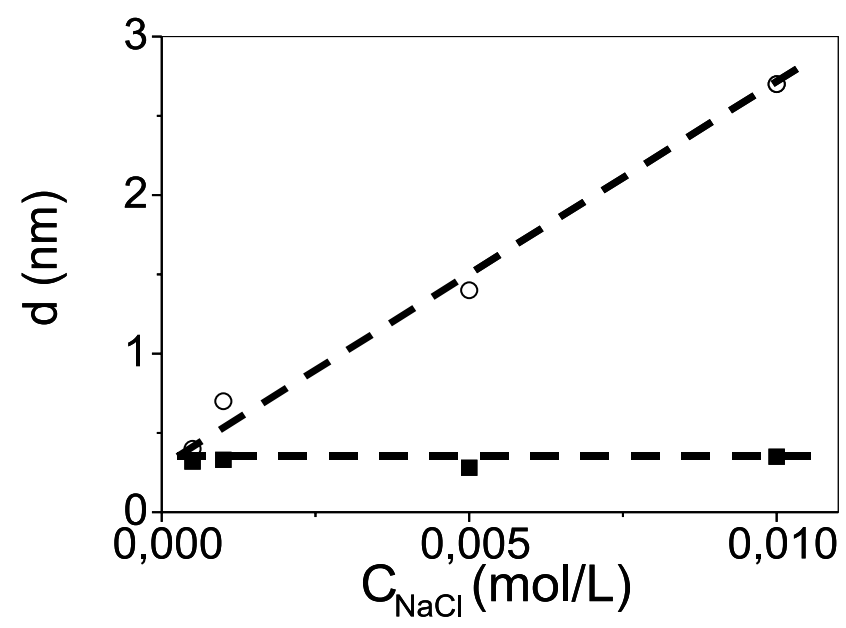

Figura 4: Espessura d (nm) do filme de quitosana adsorvida sobre CMC $\left(\bar{M}_{v}=76.000 \mathrm{~g} / \mathrm{mol}\right)$ em função do concentração de $\mathrm{NaCl}$ no meio. (ם) $\overline{G S}$ $=0,8$ e (O) $\overline{G S}=1,8$. As linhas servem apenas de guias

\section{Adsorção de BSA sobre CMC}

A imobilização de BSA sobre superfícies de CMC1 e CMC6 foi investigada em função do $\mathrm{pH}$. Nestes sistemas a massa molar média viscosimétrica da CMC foi mantida constante e o $\overline{G S}$ foi variado de 0,8 (CMC1) para 1,8 (CMC6). As superfícies de CMC permaneceram durante $4 \mathrm{~h}$ em contato com solução aquosa de BSA $(c=1,0 \mathrm{~g} / \mathrm{L})$ na faixa de $\mathrm{pH}$ de 2,4 a 6,7 .

A Figura 5 mostra as quantidades de BSA adsorvida sobre superfíceis de CMC6 e CMC1 em função do $\mathrm{pH}$. A primeira observação importante é que quando o substrato é formado por CMC6 (maior $\overline{G S}$ ), a quantidade de BSA adsorvida é maior do que quando o substrato é formado pela $\mathrm{CMC} 1$, ou seja com menor $\overline{G S}$. Estes 


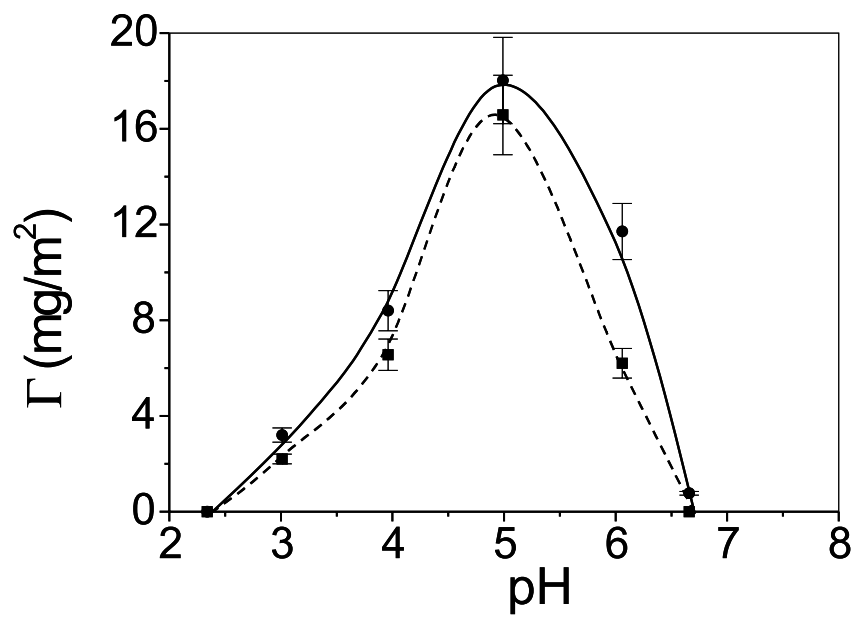

Figura 5: Quantidade de BSA adsorvida sobre CMC $\left(M_{v}=76.000 \mathrm{~g} / \mathrm{mol}\right)$ em função do $\mathrm{pH}$. (ロ) $\overline{G S}=0,8$ e $(\bullet) \overline{G S}=1,8$. As linhas servem apenas de guias

resultados mostram um comportamento semelhante ao observado na adsorção de quitosana sobre CMC. Um aumento na densidade de carga do polieletrólito favorece a adsorção do adsorbato e a formação de multicamadas ${ }^{21,22}$.

O processo de adsorção de proteínas é mais complexo do que o de polieletrólitos. Considerando que proteínas são macromoléculas muito complexas com regiões polares, hidrofóbicas e carregadas, as interações entre proteínas e substratos sólidos podem ser de natureza eletrostática, hidrofóbica ou através de ligações de hidrogênio. Entretanto, Ladam e colaboradore ${ }^{22}$ mostraram que a variação de entalpia envolvida no processo de adsorção de proteínas é geralmente positiva, qualquer que seja o substrato. A adesão de proteínas sobre superfícies sólidas é, provavelmente, dirigida por rearranjos estruturais com quebra de estruturas secundárias e terciárias, levando a um ganho entrópico que compensa os valores positivos de variação entálpica e tornando o processo de adsorção espontâneo.

As quantidades de BSA adsorvida sobre as superfíceis de CMC6 e CMC1 variaram significativamente em função do $\mathrm{pH}$, como mostra a Figura 4. A variação do $\mathrm{pH}$ do meio provoca mudança nas cargas da superfície sobre a qual BSA adsorverá, assim como nas cargas dessa proteína. Em pH próximo a 2 a densidade de carga na superfície é muito baixa devido à fraca dissociação dos grupos $\mathrm{COOH}\left(\mathrm{pK}_{\mathrm{a}} \sim 4.0\right)$, enquanto as aminas terminais das proteínas devem estar protonadas. A ausência de interações específicas leva a uma fraquíssima adsorção. Aumentando o pH até 4, as interações de natureza eletrostática entre os grupos carboxilato do substrato e as aminas terminais da proteína são favorecidas, levando a um aumento na quantidade de BSA adsorvida. Próximo a pH 5 observa-se um máximo na adsorção. Este $\mathrm{pH}$ coincide com o ponto isoelétrico da $\mathrm{BSA}^{14}(\mathrm{pI}=5.5)$. Nesta situação temos um substrato com alta densidade de carga, enquanto o adsorbato apresenta carga total zero, o que diminui sua solubilidade e favorece a adsorção. As quantidades de BSA adsorvida sobre CMC1 e CMC6 são superiores àquelas observadas para monocamadas ${ }^{23}$, indicando que os filmes de polissacarídeos são substratos promissores para o desenvolvimento de biossensores, nos quais a imobilização da proteína tem um papel decisivo. $\mathrm{O}$ fenômeno de adsorção cooperativa de proteínas é bem conhecido na literatura ${ }^{23,24}$ e pode também estar contribuindo para os altos valores de BSA adsorvida. Em $\mathrm{pH}$ próximo a 7 os grupos carboxilatos terminais da proteína também estão desprotonados, tornando-a negaticamente carregada e aumentando sua solubilidade. Apesar da repulsão entre os carboxilatos da superfície e do substrato, observa-se uma fraca adsorção, a qual é provavelmente causada por ligações de hidrogênio entre as hidroxilas dos polissacarídeos na superfície e grupos polares da proteína. Comportamento semelhante ao da Figura 4 foi também observado por Norde e Lyklema $^{25}$ para a adsorção de albumina humana sobre hematita, poliestireno e polioximetileno.

\section{Adsorção de BSA sobre quitosana (SiO2/ APS/ CMC/ Quitosana/ BSA)}

A adsorção de BSA sobre substratos formados por quitosana adsorvida sobre monocamadas de CMC1 e CMC6 foi investigada em função do $\mathrm{pH}$, apesar da quitosana não formar filmes homogêneos sobre CMC, como já discutido acima. Os substratos foram colocados durante $4 \mathrm{~h}$ em contato com solução aquosa de BSA (c = $1,0 \mathrm{~g} / \mathrm{L}$ ) na faixa de $\mathrm{pH}$ de 2,3 a 7. Os resultados obtidos estão apresentados na Figura 6 . A curva obtida é semelhante àquela obtida na Figura 5, onde o substrato era formado por CMC. Novamente um máximo de adsorção foi observado na região próxima ao ponto isoelétrico da BSA porém, os valores da quantidade de BSA adsorvida sobre superfícies recobertas somente por CMC são bem maiores. Para controle, as espessuras dos filmes secos de BSA foram medidos em diferentes pontos da mesma amostra, e pelo menos em triplicata, obtendo-se valores homogêneos, com desvio padrão inerente ao método (5\%). Entretanto, os resultados a partir da elipsometria não permitem concluir se as biomoléculas de BSA estão adsorvidas sobre os vales formados entre os aglomerados de quitosana ou sobre os dois polissacarídeos. A Figura 7 apresenta um possível arranjo para o sistema de multicamadas formado por CMC, quitosana e BSA.

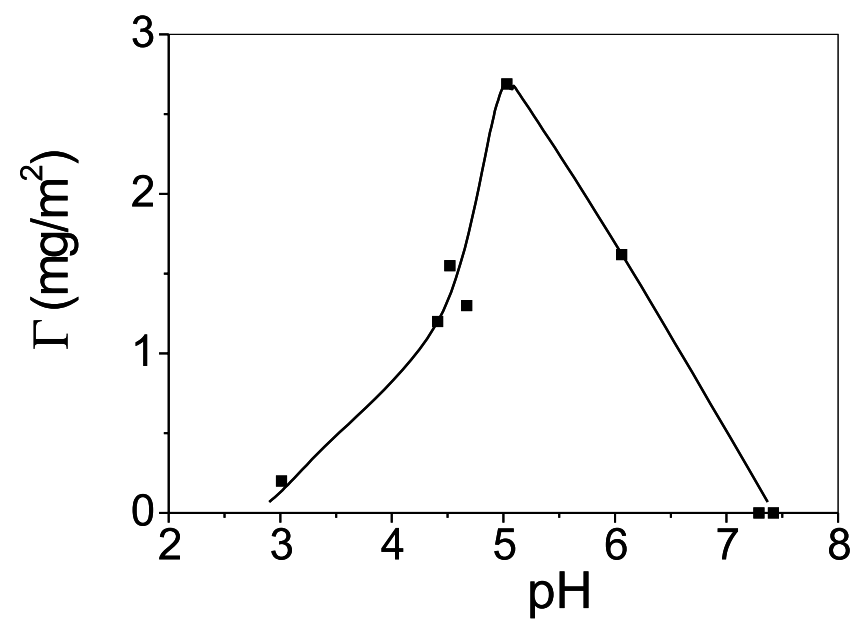

Figura 6: Quantidade de BSA adsorvida sobre quitosana em função do pH. A linha serve apenas de guia

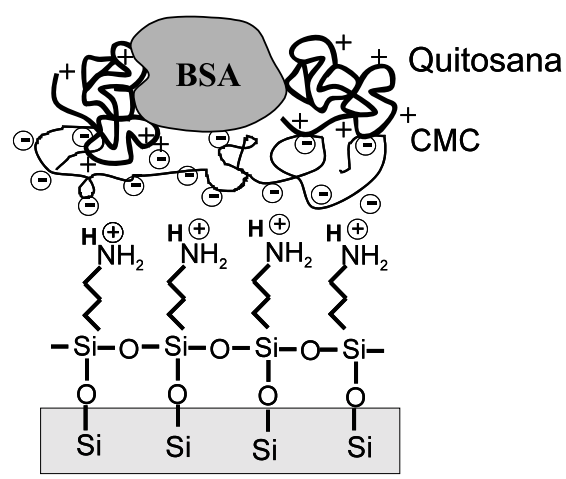

Figura 7: Esquema representando um possível arranjo para a adsorção de BSA sobre o substrato formado por CMC e quitosana 


\section{CONCLUSÕES}

A principal conclusão deste trabalho é que as variações da massa molar e do grau médio de substituição da CMC não influenciaram a adsorção da mesma sobre as superfícies amino-funcionalizadas, mas a variação do grau médio de substituição da CMC influenciou a adsorção de camadas subsequentes de quitosana e BSA. Portanto, na construção de dispositivos formados por multicamadas de polieletrólitos, o grau médio de substituição das camadas iniciais deve ser o mais alto possível, uma vez que este tem um papel decisivo na adsorção das próximas camadas. A imobilização de BSA sobre as superfícies de polissacarídeo é controlada pelo $\mathrm{pH}$ do meio. Próximo ao ponto isoelétrico da proteína, a adsorção da mesma é especialmente favorecida.

\section{AGRADECIMENTOS}

Os autores agradecem à Fapesp e ao CNPq pelo apoio financeiro.

\section{REFERÊNCIAS}

1. Napper, D. H.; Polymeric Stabilization of Colloidal Dispersions, Academic Press: London, 1983.

2. Eggins, B.; Biosensors an Introduction, Wiley \& Sons: New York, 1997.

3. Chibata, I.; Tosa, T.; Sato, T.; Mori, T.; Immobilized Enzymes, Wiley \& Sons: New York, 1978.

4. Juste, K. E.; Majewicz, T. G. Em Encyclopedia of Polymer Science and Engineering; Kroschwitz, J. I., ed.; 2 ${ }^{\text {nd }}$ ed., ; John Wiley \& Sons: New York, 1985 , v.3, p. 226

5. Morais, L. C.; Campana Filho, S. P.; Polímeros: Ciência e Tecnologia 1999, Out/Dez, 46.
6. Hoogendam, C.W.; de Keizer, A.; Cohen Stuart, M.A.; Bijsterbosch, B.H.; Batelaan, J.G.; van der Horst, P.M.; Langmuir 1998, 14, 3825.

7. Cohen Stuart, M.A.; Fokking, R.G.; van der Horst, P.M.; Lichtenbelt, J.W. Th.; Colloid Polym. Sci. 1998, 276, 335.

8. Fujimoto, J.; Petri, D.F.S.; Langmuir 2001, 17, 56.

9. Hoogendam, C.W.; de Keizer, A.; Cohen Stuart, M.A.; Bijsterbosch, B.H.; Smit, J.A.M.; van Dijk, J.A.P.P.; van der Horst, P.M.; Batelaan, J.G.; Macromolecules 1998, 31, 6297.

10. Van de Steeg, H.G.M.; Cohen Stuart, M.A.; de Keizer, A.; Bijsterbosch, B.H.; Langmuir 1992, 8, 2538.

11. Shiratori, S.S.; Rubner, M.F.; Macromolecules 2000, 33, 4213.

12. Clark, S.L.; Hammond, P.T.; Langmuir 2000, 16, 10206.

13. Roberts, G. A. F.; Chitin Chemistry; The Macmillan Press Ltd, $1^{a}$ ed., 1992

14. Carter, D. C.; Ho, J. X. Em Advances in Protein Chemistry; Academic Press: Huntsville/Alabama, 1994, v. 45.

15. Petri, D. F. S.; Schimmel, T.; Wenz G.; Schunk, P.; Langmuir 1999, 15, 4520.

16. Azzam, R.M.A.; Bashara, N.M.; Ellipsometry and Polarized Light, North Holland Publication: Amsterdam, 1987.

17. Brandrup, J.; Immergut, E.H.; Polymer Handbook, $2^{\text {nd }}$ ed., John Wiley \& Sons: New York, 1966.

18. Edward P. ; Handbook of optical constants of solids, Academic Press Inc.: Londres, 1985.

19. Siqueira, D.F.; Breiner, U.;Stadler, R.; Stamm, M.; Langmuir 1995, 11, 1680.

20. Motchmann, H.; Stamm, M.; Toprakcioglu, Ch.; Macromolecules 1991, 24, 3229.

21. Decher, G.; Science 1997, 277, 1232

22. Ladam, G.; Schaaf, P.; Cuisinier, F.J.G.; Decher, G.; Voegel, J.C.; Langmuir 2001, 17, 878

23. Lyklema, J.; Norde, W.; Prog. Colloid Polym. Sci. 1996, 101, 9.

24. Tilton, R. D.; Robertson, C.R.; Gast, A. P.; J. Colloid Interface Sci. 1990, 137, 192.

25. Norde, W.; Lyklema, J.; Colloids Surf. 1989, 38, 1. 